\title{
La enseñanza de la historia, los jóvenes y la política
}

\section{History teaching, youth and politics}

\section{O ensino de história, os jovens e a política}

\author{
María Cristina Garriga* \\ Valeria Morras* \\ Viviana Pappier ${ }^{* * *}$
}

\begin{abstract}
Resumen: El trabajo forma parte del proyecto de investigación piloto "Los jóvenes frente a la Historia" cuyo objetivo es abordar el estado actual de la enseñanza y del aprendizaje de la Historia en Argentina, Brasil y Uruguay. El artículo centra su análisis en las respuestas a las preguntas referidas a los gobiernos militares, la democracia y el futuro de los jóvenes, presentes en una encuesta que realizaron en el 2008 alumnos de 15 y 16 años de distintas escuelas de la Argentina para acercarnos a sus conocimientos sobre dichos conceptos y al papel de la enseñanza de la Historia en su construcción. Al mismo tiempo se utilizan registros de clases de escuelas secundarias de la ciudad de La Plata para conocer de modo cualitativo las modalidades concretas que asumen las prácticas de la enseñanza en historia en las aulas. Por último tratamos de dialogar con lo que consideramos que sucede hoy entre los jóvenes y la política.
\end{abstract}

Palabras clave: Gobiernos militares. Participación política. Enseñanza de la historia.

\begin{abstract}
This work is part of the research project "Youthfaced withHistory", whose goal is to address the current state of teaching and learning of History in Argentina, Brazil and Uruguay. The paper focuses its analysis on responses given to questions relating to military rule, democracy and the future of young people in a survey applied in 2008, among students between 15 and 16 years from different schools of Argentina, to verify their knowledge onthose concepts and on the role of History teaching in its construction. At the same time, class records from schools in the city of La Plata are used to qualitatively approach concrete procedures that control the practices of History teaching in classrooms. Finally, we engage ourselves in a dialogue with what we think is happening today among young people regarding politics.

Keywords: Military rule. Political participation. History teaching.

\footnotetext{
*Universidad Nacional de La Plata - Argentina. E-mail: <pinagarriga@yahoo.com.ar>

** Universidad Nacional de La Plata, Universidad Nacional de Quilmes - Argentina. E-mail: <vmorras@ gmail.com>

*** Universidad Nacional de La Plata - Argentina. E-mail: <vpappier@yahoo.com>
} 
Resumo: Este trabalho faz parte do projeto de pesquisa "Los jóvenes frente a la Historia" cujo objetivo é abordar o estado atual do ensino e aprendizagem de História na Argentina, Brasil e Uruguai. $\mathrm{O}$ artigo centra a sua análise em respostas às perguntas referentes aos governos militares, à democracia e ao futuro dos jovens, presentes em uma enquete aplicada no ano de 2008, entre alunos de 15 e 16 anos, de diferentes escolas da Argentina, para certificarmos de perto seus conhecimentos sobre ditos conceitos e sobre o papel do ensino da História na sua construção. Ao mesmo tempo, se utilizam registros de aulas de escolas de ensino médio da cidade de La Plata para conhecer de modo qualitativo as modalidades concretas que assumem as práticas do ensino em história nas salas. Por último, nos dedicamos a dialogar com o que consideramos que acontece hoje entre os jovens e a política.

Palavras-chave: Governos militares. Participação política. Ensino da História.

\section{Presentación}

El proyecto de investigación piloto "Los jóvenes frente a la Historia", dirigido por Luis Cerri y Gonzalo de Amézola, cuyo objetivo es abordar el estado actual de la enseñanza y del aprendizaje de la Historia en Argentina, Brasil y Uruguay, busca obtener información sistemática sobre las modalidades que adopta la enseñanza de la historia a partir de los cambios de paradigmas en la didáctica de la historia en los años 80, coincidiendo en América Latina con el fin de gobiernos militares y el inicio de etapas democráticas. La investigación intenta aportar datos empíricos para responder interrogantes tales como: “QQué piensan los jóvenes argentinos, brasileños y uruguayos sobre la Historia, la identidad nacional y la política? ¿Cómo se posicionan políticamente? ¿Cómo se les presenta la enseñanza de la Historia (contenidos, metodologías, concepciones teóricas)? ¿De qué manera esa enseñanza puede responder mejor a las demandas de una educación de calidad?".

Una de las herramientas utilizadas para recolectar información es un cuestionario que en términos generales sigue los lineamientos del presentado en el proyecto europeo "Youth and History" con adaptaciones ligadas al contexto de América Latina, referidas en especial a las dictaduras militares, la mujer, la visión de otros países latinoamericanos. El cuestionario incluye temas sobre los cuales los alumnos responden señalando el nivel de su concordancia con las afirmaciones propuestas a través de la escala de Likert.

Los dos conceptos que orientan el trabajo de investigación son: "conciencia histórica" y "cultura política". Por un lado, la conciencia histórica, según Rüsen (1992), es una operación del intelecto humano que da sentido a la experiencia del tiempo y tiene una función práctica haciendo efectiva una orientación

\footnotetext{
${ }^{1} \mathrm{El}$ proyecto piloto se inició en al año 2008. En la actualidad estamos nuevamente recopilando datos a través de la encuesta con algunas modificaciones y se han incorporado al proyecto denominado "Los jóvenes y la historia en el MERCOSUR" Venezuela y Paraguay.
} 
temporal en la vida diaria a través de la mediación de la memoria histórica. El autor considera que esta "tiene su representación en una interpretación de la experiencia del pasado encaminada a poder comprender las actuales condiciones de vida y a desarrollar perspectivas del futuro de la práctica vital conforme a la experiencia" (RÜSEN, 1997, p.81). Rüsen (1992) define al desarrollo de la conciencia histórica como un proceso de aprendizaje de naturaleza histórica, al tiempo que social, cultural y cognoscitivo.

Por otro lado, siguiendo a Almond y Verba apud Borba (2005, p. 148), entendemos por "cultura política" al concepto que se refiere "a las orientaciones específicamente políticas, las actitudes respecto al sistema político, sus diversas partes y el papel de los ciudadanos en la vida pública”.

El presente trabajo centra su análisis en las respuestas obtenidas en Argentina a las preguntas referidas a los gobiernos militares, la democracia y el futuro de los jóvenes. Las encuestas se administraron en 2008 a jóvenes de distintas escuelas de las ciudades de Santa Fe, La Plata, Malvinas Argentinas, San Miguel y José C. Paz, de entre 15 y 16años con el objetivo de acercarnos a sus conocimientos sobre los conceptos enunciados y al papel de la enseñanza de la Historia en su construcción. Las encuestas administradas en las ciudades mencionadas suman 535. En cada una de las ciudades se seleccionaron tres escuelas públicas de gestión estatal (centro, periferia y excelencia) y dos de gestión privada (confesional y laica).

Al mismo tiempo se utilizan registros de clases de escuelas secundarias de la ciudad de La Plata para conocer de modo cualitativo las modalidades concretas que asumen las prácticas de la enseñanza en historia en las aulas.

La escala de Likert o escala de actitudes es "una manera de medir cómo las personas perciben alguna cosa, sea un grupo de personas, una cuestión social o una experiencia de vida [...] los investigadores elaboran una escala haciendo a los encuestados cierto número de preguntas, todas ellas relacionadas con la cuestión pautada y que los invita a acordar o a no estar de acuerdo con las afirmaciones [...]" (JOHNSON, 1997, p. 87 apud CERRI; AMÉZOLA, 2009). Se elaboraron cinco niveles que varían de "desacuerdo totalmente, desacuerdo, acuerdo en parte, acuerdo, acuerdo totalmente"; "muy difícilmente, difícilmente, tal vez, probablemente, muy probablemente"; "muy poca, poca, media, importante, muy importante", escala a partir de la cual se atribuyen valores numéricos a cada respuesta (de -2 a -1 para la respuesta más negativa, 0 para las respuestas neutras y de 1 a 2 para las respuestas más positivas). El tratamiento es la producción de medias que permiten ver la concordancia media con cada afirmación y la definición de desvío del patrón, lo que a su vez hace posible conocer la media de variación de las respuestas (CERRI; AMEZOLA, 2009). En este trabajo nos 
limitamos a analizar las respuestas de los estudiantes argentinos para algunas de las preguntas del cuestionario referidas a nuestro tema. Esas preguntas son: ¿Cómo pensás que era la vida en tu país hace 40 años?; ¿Cómo pensás que será la vida en tu país dentro de 40 años? ¿Cómo pensás que será tu vida dentro de 40 años?; ¿Qué pensás de la democracia?; y las afirmaciones referidas a los gobiernos militares.

\section{Las representaciones de la democracia y de los gobiernos militares}

La mayoría de los alumnos encuestados $(0,66)$ acuerdan en que la democracia es "el gobierno del pueblo, para el pueblo y por el pueblo". Esta valoración positiva que aparece frecuentemente en los manuales, es largamente citada en las aulas y está instalada en el sentido común desde hace un largo tiempo y, en el caso de la encuesta de referencia, es necesario vincular con aquella en la cual los jóvenes atribuyen autenticidad a la democracia si hombres y mujeres tienen iguales derechos en todas las situaciones $(0,64)$. A su vez, esta valoración positiva contrasta con la mirada negativa que surge de la disociación entre democracia y obediencia a la ley, a la justicia y a la protección de las minorías $(0,09)$.

Gráfico 1-¿Qué pensás de la democracia?

a. Es el gobierno del pueblo, para el pueblo por el pueblo

b. Es la mejor herencia de la Antigua Grecia

c. Es el resultado de un largo proceso de expreriencias y errores a lo largo de los tiempos

d. No pasa de la declamacón de algunos lideres partidarios eq 0,32 elecciones

e. Es gobernar obedeciendo a la ley y a la justicia, en protección delas minorias

f. Deberia incluir la protección de los más pobres y dar garantia de empleo

g. Es un sistema de gobierno débil que no sirve en tiempos de $-0,26$ crisis

h. Es una falsa apariencia que encubre el hecho de que son siempre los ricos los que vencen en la historia

i. No es auténtica mientras hombres y mujeres no tengan iguales derechos en todas las situaciones

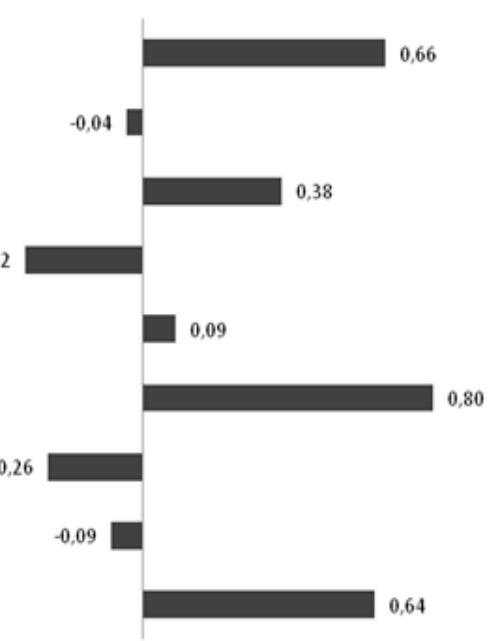

Fuente: Datos de Argentina de la investigación "Jóvenes frente a la Historia”, 2009. 
Posiblemente estas afirmaciones se correspondan en gran parte con un modo crítico de producción de sentidos por la conciencia histórica de los jóvenes respecto del tiempo signado por la crisis del 2001 que atravesó su experiencia cotidiana y la de sus familias, en la que aparece deslegitimado el rol del Estado para llevar adelante políticas públicas que mejoren las condiciones de vida de la sociedad en su conjunto.

Reconocer la democracia como el "resultado de un largo proceso de experiencias y errores a lo largo del tiempo" $(0,38)$ puede indicar, a nuestro juicio, una lectura del tiempo no como acontecimientos que se suceden linealmente para dar origen a la democracia, sino como el resultado de una construcción que supone avances y retrocesos o bien estar ligada a una enseñanza de la Historia en la que ésta es vista como la posibilidad de superar los errores del pasado o a la obligación de recordar para no repetir. En la respuesta subyace una interpretación del tiempo como transformación que supone que las experiencias pasadas son susceptibles de cambios y las formas de vida alejadas evolucionan en configuraciones más positivas en el futuro.

Por otro lado, hay un alto promedio $(0,80)$ entre los alumnos encuestados de acuerdo en que la democracia debe incluir la protección de los más pobres y dar garantía de empleo. Si leemos esta afirmación en diálogo con la perspectiva de la futura participación política de los alumnos encuestados $(-0,45)$ observamos que no se vincula el "deber" de la democracia de proteger a los más pobres y garantizar el empleo con la participación política de los ciudadanos. O bien los encuestados conciben la democracia como un concepto abstracto, cuyo deber ser incluye la construcción de una sociedad más justa, sin contemplar la participación de los ciudadanos en esa construcción, o simplemente no se involucran y se sienten ajenos a la participación política que demanda una ciudadanía activa, que como dice Alexander Ruiz Silva "significa ejercer con sentido de responsabilidad un rol político, que en buena medida se define en la participación de proyectos colectivos en los que hace tangible la idea de la construcción o reconstrucción de un orden social justo e incluyente." (RUIZ SILVA, 2009, p. 54).

Es probable, por otra parte, que muchos jóvenes relacionen la participación política con los partidos políticos o con las organizaciones construidas por los jóvenes en otros momentos de la historia, sin tener en cuenta las otras formas de participación en la construcción de la cultura y las dimensiones políticas que la misma produce (IDAES, 2006). No hay que olvidar que los cambios sociales, culturales, económicos, políticos de las últimas décadas impactan en las formas de participación

así como los ámbitos donde se experimentan las diversas modalidades de agenciamiento. De tal modo, vale la pena la valoración que los jóvenes tienen 
respecto de acciones realizadas en instancias institucionales distintas a las clásicas del mundo "político" como son las deportivas, religiosas, artísticas o civiles. Algunos jóvenes se agrupan alrededor de su pertenencia comunitaria, conformando grupos que ofrecen no sólo ámbitos de identificación poderosos hacia el interior del grupo, sino también modos de intercambio económico y social con los otros. (IDAES, 2006, p. 63).

Tal como se expresara más arriba, para los encuestados la democracia pierde autenticidad si hombres y mujeres no tienen los mismos derechos en todas las situaciones $(0,64)$. Podría deducirse de la adhesión a esta afirmación la concepción de la ciudadanía en tanto posibilidad de ejercicio de los derechos. Derechos que son declamados insistentemente en la escuela y colgados a modo de lista en sus paredes, que lejos están de la "ciudadanía activa". Creemos muy interesante leer estas respuestas a la luz de la distinción que establece Ruiz Silva entre la ciudadanía en sentido nominal y la ciudadanía en sentido activo. La primera hace referencia a la condición que el Estado otorga a una persona siguiendo un criterio legal e implica que sea portadora de derechos, en cambio la segunda remite a un criterio político y se entiende como una práctica. En la escuela, y siguiendo la tradición de la educación cívica, se buscaba conocer y respetar normas y derechos pero no un involucramiento o interferencia sobre lo que está establecido. En cambio "la reflexión ciudadana propicia la reflexión intencional sobre las finalidades y límites de la esfera política, implica el desarrollo de la capacidad deliberativa y la preparación para la participación responsable en procesos sociales y políticos." (RUIZ SILVA, 2009, p. 72). Como dice Paulo Freire

La ciudadanía realmente es una invención, una producción política. [...] La ciudadanía no llega por casualidad: es una construcción que, jamás terminada, exige luchar por ella. Exige el compromiso, claridad política, coherencia, decisión. Es por esto mismo por lo que una educación democrática no se puede realizar al margen de una educación de y para la ciudadanía. (FREIRE, 1994, p. 34).

Ahora bien, ¿qué rol juega la escuela secundaria en la construcción de ciudadanos activos para el desarrollo de la democracia? ¿Qué rol se le ha asignado a la enseñanza de la historia en este proceso? ¿Cuál es el papel que juegan el conflicto y la política en la construcción de conocimiento en la escuela?

Lo que ha caracterizado a la historia escolar ha sido una historia política donde precisamente la política ha estado ausente; es decir, donde la disputa por el poder de los diversos y enfrentados intereses, ideas y objetivos de los individuos y grupos heterogéneos no ha entrado prácticamente en las narraciones explicativas de nuestra historia. Justamente a lo largo de la historia la escuela se ha encargado de procesar los contenidos y borrarles sus aristas conflictivas, en especial 
temas polémicos que ponen en juego valores o memorias en disputa. Se ha ido conformado así un relato del pasado centrado en los próceres y acontecimientos, donde han estado ausentes los sujetos sociales y sus conflictos. Las luchas sociales, culturales y políticas prácticamente no han entrado en la enseñanza de la historia como un modo de comprender la complejidad de la formación de nuestra identidad, ni como parte del devenir histórico de la formación de la Argentina. Como así tampoco los conflictos y disputas en torno a la definición de la ciudadanía. Es que la historia argentina escolar, como sostiene Luis Alberto Romero opera menos como la explicación o el desarrollo de procesos del pasado, que como un ritual pedagógico de una educación patriótica destinada a la formación del ciudadano argentino. (ROMERO, 2004).

Tradicionalmente, la política ha tenido las puertas cerradas de la escuela, no debía entrar ya que podía alterar la supuesta tranquilidad que ha caracterizado a la institución educativa, virtud que ha sido muy valorada dentro de la cultura escolar. ${ }^{2}$ Como lo ha sostenido Inés Dussel "la institución se asemeja a una familia; el consenso, la homogeneidad y la armonía son los valores tenidos en el más alto grado, el disenso y la heterogeneidad son elementos que se perciben como amenazas a esa identidad.” (DUSSEL, 1996, p.51).

Consideramos que la persistencia de estos marcos institucionales tienden a obstaculizar la promoción de una cultura democrática, aun cuando las prescripciones curriculares y la resolución 4900/05 del 15 de septiembre de 2005 de la Dirección General de Cultura y Educación de la Provincia de Buenos Aires la promuevan. Esta última establece un modelo de estatuto para los Centros de Estudiantes que podrán constituirse en los establecimientos de educación secundaria, dado que

[...] en un contexto democrático la constitución del ciudadano incluye la toma de decisiones de dimensión social, por lo que es imprescindible que la comunidad educativa considere las demandas y cuestionamientos de sus miembros, brinde atención y espacio para sus iniciativas, y sobre todo, garantice experiencias positivas con respecto al derecho de opinar y proponer. (DGCyE, 2005, p. 1).

Justamente consideramos que la política y el conflicto, generalmente, son abordados negativamente, no sólo como contenidos sino también como modos de construcción del conocimiento, a pesar de lo que prescribe la nueva legislación.

\footnotetext{
${ }^{2}$ Se retoman aquí ideas volcadas en otros trabajos: Pappier, V. y Morras, V. "La construcción de la memoria en la escuela. Una mirada a los actores y conflictos que genera la conmemoración del 24 de marzo". Ponencia presentada en las Jornadas Interescuelas e interdepartamentales de historia, Tucumán, septiembre de 2007 y Garriga, M.C., Pappier, V. y Morras, V. "La reconstrucción del pasado reciente en la escuela". Ponencia presentada en $1^{\circ}$ Congreso Internacional de Didácticas Específicas. Universidad Nacional de General San Martín, 18-20 de junio, 2008.
} 
Precisamente, La Ley de Educación Nacional (2006) y la Ley de educación de la Provincia de Buenos Aires (2007) en su artículo 3 establecen a la educación como política de Estado para "profundizar el ejercicio de la ciudadanía democrática". Uno de los objetivos de la educación secundaria en la provincia de Buenos Aires consiste, precisamente, en "garantizar los mecanismos de participación de los alumnos en el gobierno escolar para favorecer y fortalecer el ejercicio de la ciudadanía y la gestión democrática de las instituciones del Nivel."

Asimismo, el diseño curricular de la Provincia de Buenos Aires para la actual escuela secundaria promueve "la constitución de sujetos que se autonomicen y realicen lecturas críticas de los contextos en que están inmersos, que establezcan lazos de solidaridad, que pretendan el cumplimiento de derechos y responsabilidades, y a los que se les ofrezcan saberes que las generaciones anteriores han desarrollado". (DGCyE, 2006, p. 22).

Específicamente las materias de Ciudadanía en la escuela secundaria tanto del ciclo superior como del básico, buscan concretar espacios donde estén presentes en la escuela y en la comunidad prácticas de reflexión y participación ciudadana. Se parte de una mirada a través de la cual se concibe que la ciudadanía se construye activamente buscando la formación de sujetos políticos que respeten y hagan respetar los derechos humanos y el sistema democrático, reconociendo los mismos como resultado de procesos históricos caracterizados por conflictos y luchas sociales en el mundo en general y en la Argentina en particular.

Es por ello que la asignatura Construcción de la Ciudadanía, en la secundaria básica, tiene como finalidad "fortalecer la formación de ciudadanos y ciudadanas" desde las propias prácticas juveniles, promoviendo el reconocimiento de esas prácticas "para transformarlas en parte constitutiva de las experiencias pedagógicas de la escolaridad y fortalecer la identidad, la ciudadanía y la preparación para el mundo adulto, entendiendo que su inclusión en la escuela hace posible la formación de sujetos libres para expresarse, actuar y transformar la sociedad." (DGCyE, 2006, p. 11).

Sin embargo, también podría considerarse que las formas de la organización escolar configuran distintas maneras de aprender y vivir la política y lo político que difieren de acuerdo a las características de cada institución y de las historias y expectativas de quienes asisten a ellas produciendo diferencias significativas en la construcción ciudadana. (NUÑEZ, 2010).

Consideramos que tendrá que trabajarse fuertemente desde la política educativa para que lo que se prescribe desde las normativas legales y curriculares pueda ser vivenciado y aprehendido por todos los jóvenes en todas las instituciones educativas y no quedar reducido a la mera prescripción. 
Un dato a resaltar en la línea del fortalecimiento de una ciudadanía democrática es que los jóvenes encuestados, cuyas vidas se desarrollan en democracia, manifiestan en las respuestas elegidas su rechazo a los gobiernos militares. Afirman que los mismos no respetan la opinión del pueblo $(0,98)$, como tampoco la constitución ni los derechos humanos $(0,87)$. Del mismo modo no coinciden con las afirmaciones que los relacionan con la promoción del desarrollo económico $(-0,57)$ y la defensa de la soberanía nacional $(-0,39)$, reconociéndolos como responsables de haber generado crisis económicas y deuda externa $(0,64)$. El rechazo a los gobiernos militares y a los argumentos a partir de los cuales pretendieron legitimar el golpe no puede desligarse del proceso iniciado en la segunda mitad de la década de $1990^{3}$, por los Juicios por la Verdad, la aparición de H.I.J.O.S ${ }^{4}$, la recuperación de los nietos por Abuelas de Plaza de Mayo, las marcas urbanas (placas, recuperación de espacios para la memoria, construcción de museos), la decisión del Estado de instaurar el 24 de marzo Día nacional de la memoria por la verdad y la justicia como feriado nacional inamovible ${ }^{5}$ y la incorporación a los contenidos curriculares de los procesos históricos y políticos que hicieron posible el terrorismo de Estado.

\footnotetext{
${ }^{3}$ Denominado por G. Cerrutti "boom de la memoria". Cerrruti G. Entre la fetichización y el duelo. La Historia de la Memoria. Revista Puentes. Comisión Provincial por la Memoria. Marzo 2001.

${ }^{4}$ H.I.J.O.S. (Hijos e Hijas por la Identidad y la Justicia contra el Olvido y el Silencio) es una organización, creada en 1995, que está integrada por hijos de desaparecidos, asesinados, presos políticos, exiliados durante la dictadura militar y sus años anteriores. Sus objetivos son la lucha contra la impunidad, la reconstrucción fidedigna de la Historia, la restitución de la identidad de los hermanos y familiares secuestrados y apropiados, así como la reivindicación de la lucha de sus padres y sus compañeros.

${ }^{5}$ En Argentina, la Ley Nacional de Educación n²6.206 (2006) establece en el Art. 92: Formarán parte de los contenidos curriculares en todas las jurisdicciones: [...] c) El ejercicio y construcción de la memoria colectiva sobre los procesos históricos y políticos que quebraron el orden constitucional y terminaron instaurando el terrorismo de Estado, con el objetivo de generar en los/as alumnos/as reflexiones y sentimientos democráticos y de defensa del Estado de Derecho y la plena vigencia de los Derechos Humanos, en concordancia con lo dispuesto por la Ley $\mathrm{n}^{\circ} 25.633$.
} 
Gráfico 2 - Sobre los gobiernos militares

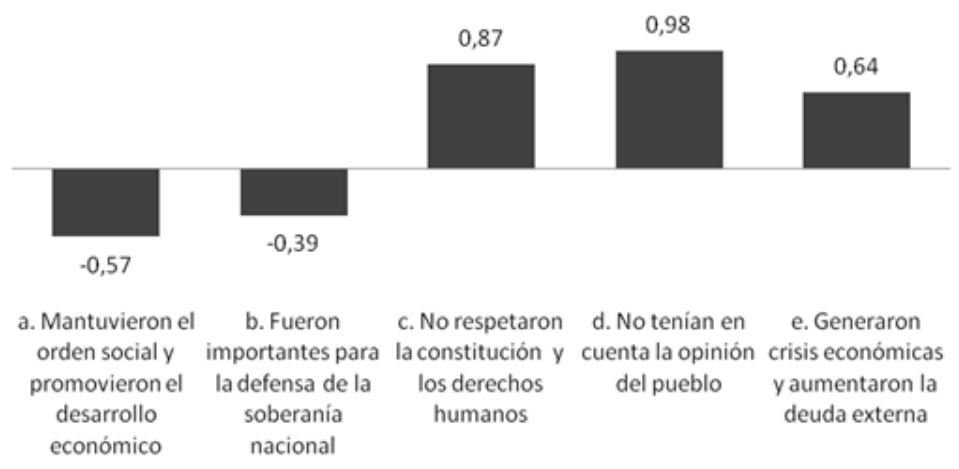

Fuente: Datos de Argentina de la investigación “Jóvenes frente a la Historia”, 2009.

Particularmente nos preguntamos ¿En qué medida la escuela contribuye al desarrollo de prácticas de participación ciudadana de los adolescentes? ¿Son convocados a la participación colectiva? ¿Las clases de historia son una instancia para la reflexión acerca de las prácticas políticas y las participaciones activas que han desarrollado los sujetos sociales? ¿La enseñanza de la historia contribuye a que los adolescentes se sientan sujetos sociales partícipes de la historia, de la sociedad en la cual viven?

Al mismo tiempo nos preguntamos qué sentido histórico construye la escuela. Y cómo acercar a los alumnos a nuevos horizontes de experiencia temporal, dado que "el aprendizaje de la historia es un proceso de digestión de experiencias del tiempo en forma de competencias narrativas. La 'competencia narrativa' se entiende aquí como la habilidad para narrar una historia por la cual la vida práctica recibe una orientación en el tiempo”. (RÜSEN, 1992, p.94).

\section{Las representaciones del pasado, del futuro y de la participación política}

Las respuestas acerca de cómo piensan los adolescentes la vida del país hace cuarenta años hacen referencia a una vida política agitada por conflictos políticos $(1,03)$, donde estén presentes problemas entre ricos y pobres (aunque en menor proporción que los conflictos políticos $(0,64)$, poco ligada a la prosperidad y a la riqueza $(-0,39)$. 
Gráfico 3 - ¿ Cómo pensás que la vida en tu país hace 40 años?

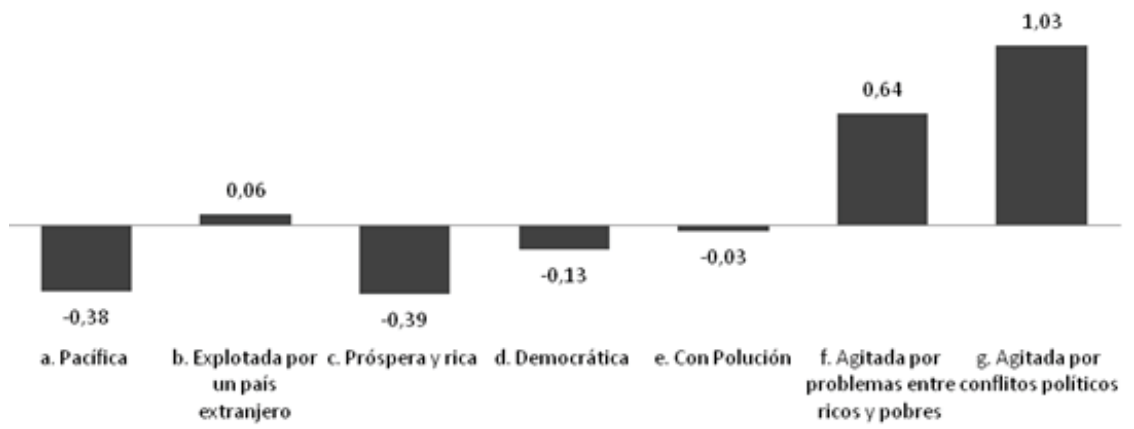

Fuente: Datos de Argentina de la investigación “Jóvenes frente a la Historia”, 2009.

Es interesante observar en esta respuesta una caracterización de ese período como difícilmente democrática $(-0,13)$, pues nos remite a una pregunta consignada anteriormente en la cual la democracia es vinculada a la vigencia de los derechos y a la necesidad de protección de los más débiles.

Esta perspectiva no se aleja de su percepción sobre la vida del país dentro de cuarenta años pues la mayoría continúa con su visión acerca de que será una vida agitada por conflictos políticos $(1,02)$ y en segundo lugar agitada por problemas entre ricos y pobres $(0,85)$, con mucha contaminación ambiental $(0,78)$, tal vez democrática $(0,35)$ y difícilmente próspera, rica $(-0,47)$ y pacífica $(-0,56)$.

Gráfico 4 - ¿ Cómo pensás que será la vida en tu país dentro de 10 años?

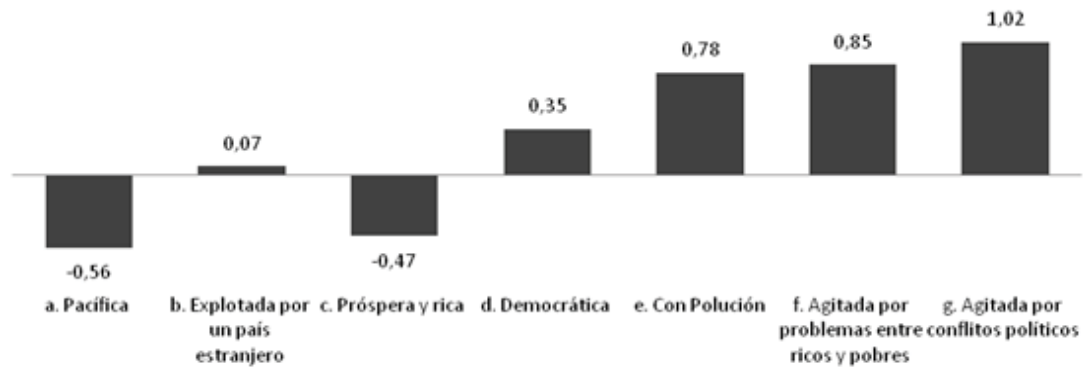

Fuente: Datos de Argentina de la investigación “Jóvenes frente a la Historia”, 2009. 
$\mathrm{Al}$ parecer, por los resultados relevados, el concepto de democracia parecería estar más vinculado a problemáticas de índole social o económica que a cuestiones de índole política, cuya dimensión parecería quedar más vinculada a la política partidaria. La amplia mayoría de los jóvenes encuestados no se imagina su futuro participando en la vida política $(-0,45)$. Predominan otras representaciones individuales o referidas al ámbito más privado como tener una familia armoniosa y feliz $(0,85)$, muchos amigos $(1,11)$. Consideran que tendrán un trabajo placentero $(0,70)$, rendimientos elevados $(0,62)$ y que dispondrán, tal vez, de tiempo libre para participar en actividades de ocio y recreación $(0,43)$. A pesar de ser menor en proporción, todos imaginan tener libertad política e individual $(0,64)$. Los jóvenes encuestados, en general, pareciera que no se perciben involucrados directamente en la sociedad en la que viven.

Gráfico 5 - ¿ Cómo pensás que será TU vida dentro de 40 años?
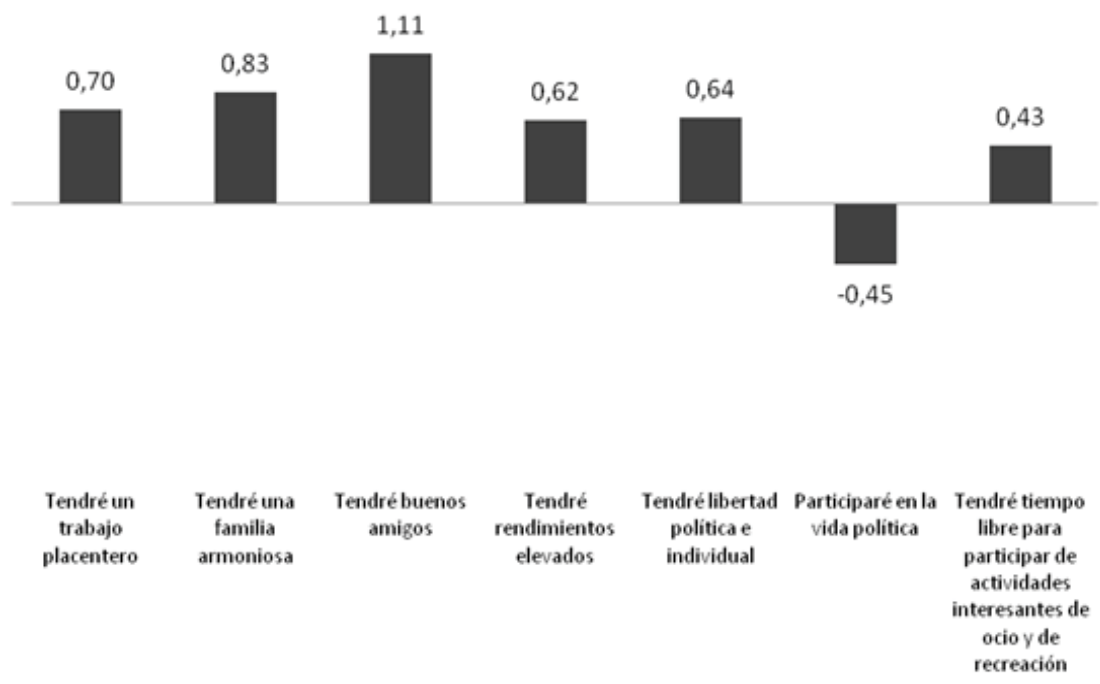

Fuente: Datos de Argentina de la investigación “Jóvenes frente a la Historia”, 2009.

Como puede observarse, los alumnos que respondieron el cuestionario poseen una mirada optimista sobre su futuro, en términos individuales y familiares, a pesar del contexto de "agitación" señalado anteriormente. Una mirada donde no se muestra un marcado interés se vincula con la participación política y su relación con un proyecto colectivo para construir un orden social más justo, que creemos está asociada con la concepción política forjada en los 
noventa, en la cual el epicentro se encuentra en el sujeto y no en la colectividad, una mirada individual que no es patrimonio exclusivo de los jóvenes encuestados.

En el contexto en que fueron administradas las encuestas es válida la afirmación de Javier Auyero quien sostiene que se ha configurado una ciudadanía de "baja intensidad", al hacerse presente la disminución de las aspiraciones de ejercicio de los derechos sociales, legales e institucionales (AUYERO, 1994). De este modo, la política deja de ser vista por muchos como mecanismo para resolver los conflictos. Así, ante un futuro no muy auspicioso, según sus proyecciones, en términos de conflictos políticos, conflictos entre sectores sociales y problemas ambientales, pareciera que una gran mayoría no se involucraría. Se ha desarrollado una política de la inacción, de la no participación. El individualismo y la vida privada pareciera que están triunfando sobre lo colectivo y la participación en la vida pública.

Sin embargo, las normativas legales y curriculares mencionadas y la participación activa actual en diversos movimientos juveniles, pone en cuestión la respuesta en que los jóvenes encuestados, en 2008, minimizan la participación política.

\section{Un presente que cambia}

Tal como sostiene el filósofo chileno Martín Hopenhayn,

[...] la juventud hoy en día aparece, o bien porque tiene un manejo de información que la hace sentirse más empoderada políticamente o bien porque la política se abrió como un campo que ya no responde a un pensamiento único. Hay una percepción mucho más generalizada de que la política deja de ser una especie de administración mecánica del aparato burocrático público para ser un espacio donde se pueden tomar decisiones para modificar la sociedad. (Entrevista a Martin Hopenhayn, Pagina 12, 2 de enero de 2012).

En este sentido, un sondeo hecho para dar cuenta del interés por la política de los jóvenes - entre 15 y 17 años - realizado recientemente por la consultora Ibarómetro en la Ciudad de Buenos Aires, primero y segundo cordón del Conurbano, arroja como resultado que casi un 42 por ciento de los encuestados manifiesta estar interesado "bastante" y "mucho" en la política. El 47 por ciento de los jóvenes manifiesta estar a favor del voto a los 16 años; mientras que un 58 por ciento expresa que de poder hacerlo, aunque fuese optativo, iría a votar. Al ser consultados en torno a la pregunta "¿Dónde surgió tu interés por la política?", un 62 por ciento dijo "De lo que está pasando en el país", un 15 por ciento "De mis padres", un 11,4 por ciento "Del colegio" y apenas un 3,3 por ciento "De mis amigos". Ignacio Ramírez, el director de la consultora, comenta que tradicionalmente la fuente del interés por el debate político eran el hogar, los 
padres, incluso el colegio, en cambio "ahora lo que está politizando a los chicos es el contexto político, un ecosistema cultural que transita la Argentina, en el que el principal arquitecto es la propia agenda kirchnerista que politiza e inaugura debates que implican asumir un punto de vista." (NORA, 2012).

Muestra de esa participación es la toma de aproximadamente 40 colegios secundarios, entre técnicos, normales, comerciales y artísticos, en la Ciudad Autónoma de Buenos Aires, desde el 17 de septiembre del corriente año, en contra de la reforma curricular que proponía el gobierno de Mauricio Macri para el nivel medio. Justamente uno de los reclamos de los estudiantes es poder opinar directamente sobre ese proceso que responde a una directiva del Consejo Federal de Educación (CFE), por el cual los planes de estudios de las escuelas técnicas deben homologarse para que los títulos posean el mismo valor en diferentes distritos. Al momento de escribirse este artículo el ministro de Educación de la Ciudad Autónoma de Buenos Aires presentó una propuesta de participación de los alumnos y docentes en nueve jornadas a realizarse en el año 2013. Dichas jornadas "constarán de tres etapas: informativa, con material ofrecido por el Ministerio; participativa y deliberativa, y de definición institucional." (Diario La Nación, 5 de octubre de 2012).

Ahora bien ¿en qué medida la escuela contribuye al desarrollo de prácticas de participación ciudadana de todos los actores involucrados en la vida escolar? ¿Las clases de historia son una instancia para la reflexión acerca de las prácticas políticas y la participación activa que han desarrollado los sujetos sociales? ¿La enseñanza de la historia contribuye a que los adolescentes se sientan sujetos sociales partícipes de la historia de la sociedad en la cual viven? ¿En qué medida la escuela favorece el aprendizaje de las competencias narrativa que permiten experimentar el tiempo pasado, interpretarlo históricamente y darle uso práctico vital?

En nuestras recorridas por las escuelas como formadores de profesores de historia percibimos que nuevas experiencias se están gestando: formación de nuevos centros de estudiantes, debates en torno al voto a los 16 años, escuelas tomadas en Capital Federal reclamando ante la posibilidad de cambiar los programas educativos. Estas experiencias dan cuenta de nuevas formas de participación de los jóvenes y de una consideración de la política a través de una mirada de reconocimiento y validez para pensar y actuar en el presente al mismo tiempo que demandan que se los incluya como protagonistas.

Sin embargo las transformaciones también presentan contradicciones y tensiones que son interesantes de presentar cualitativamente desde la riqueza que aportan los registros de clase. ¿Qué lugar ocupan los jóvenes en ellos? ¿Qué mirada han construido de sí mismos en torno a su participación? ¿Qué 
lugar tienen los adultos en la construcción de la cultura política con la cual se identifican? Para responder a algunos de estos interrogantes nos adentraremos en la complejidad del aula a través de algunos registros de clases del año 2012.

En una escuela pública de la ciudad de La Plata, que cuenta con un centro de estudiantes desde hace unos años, el debate en torno al decreto de "desperonización" ejecutado por la autollamada Revolución Libertadora, que derrocó a Perón en 1955, es la excusa para discutir sobre el presente. En los argumentos de los chicos aparece la discusión sobre la denominación "libertador" de un gobierno que llega a través de un golpe y que prohíbe hasta tener una foto del General Perón. Al respecto un alumno señala que es similar a lo que ocurre en la realidad actual argentina pues: "No hay libertad de expresión". El grupo en su conjunto discute ampliamente sobre el significado y alcance de esa afirmación. Otra de las voces sostiene que si no existiera la libertad de expresión los medios de comunicación no podrían publicar todo lo que hoy publican, ni se permitirían actos de protesta contra el gobierno como los "cacerolazos". Esta discusión los remite a plantearse si el voto a los 16 años no se asocia a una búsqueda de mayor libertad de expresión. Afirmación que hace dudar a muchos alumnos que expresan que aún les faltan años y experiencias para poder votar. Otros advierten que la entrega de las netbook tiene como intención la "captura" de los votos de los jóvenes. Sin embargo el docente a cargo del curso, contrapuso esas afirmaciones al debate originado en la comparación sobre los derechos en los años ' 50 y la actualidad', y a las diversas razones que sustentaron las posiciones de los alumnos, quiénes esgrimían razones bien fundadas, La docente señala, con entusiasmo, que tal discusión se prolonga en el recreo, situación que demuestra el compromiso de los alumnos.

En el registro mencionado nos parece interesante resaltar dos cuestiones: una centrada en la historización de la política y la otra en la mirada que los alumnos construyen sobre su lugar en la historia y su vinculación con la política.

En el registro de clase, al que se hace referencia, no solo se incluye a los gobiernos en la realidad social sino como expresiones de conflictos sociales. Es posible de ese modo pensar la multiplicidad de tiempos históricos con sus continuidades y rupturas.

Asimismo es interesante remarcar cómo muchos jóvenes consideran positiva la política pero se miran desde el lugar de la "falta" del "no poder" que se corresponde con la mirada de los adultos.

\footnotetext{
${ }^{6}$ Forma de protesta a través de la cual los manifestantes se expresan haciendo ruido con cacerolas, ollas u otros utensilios domésticos. Adquirió gran fuerza en Argentina con la crisis política, institucional, económica y social de diciembre de 2001.

${ }^{7}$ En la clase el docente puso a disposición de los alumnos fuentes correspondientes a diversas posiciones.
} 
En otras dos escuelas públicas de La Plata recientemente están formando sus centros de estudiantes e invitan a muchos jóvenes a sumarse a esta experiencia. En una de ellas, periférica, sin tradición de participación estudiantil, dos miembros del equipo de gestión comunican a los alumnos esta noticia en el medio de una clase. Si bien consideran valioso que la escuela posea un centro de estudiantes y que los chicos participen en las votaciones, en el discurso que les dirigen no abren la posibilidad de diálogo sino que, "imperativamente" apelan una y otra vez, a que organicen una lista opositora. Si bien no consideramos esa demanda como negativa en sí misma, el adulto no invita desde esas afirmaciones a valorar el centro como canal de participación que se va construyendo con aportes y discusiones a través del tiempo. Apelar, entonces, a la conformación de una lista opositora cuando sólo faltan dos días para que se realicen las votaciones, es de algún modo quitarle mérito al tiempo de búsqueda y de compromiso a quiénes organizaron la única lista que se presenta a las elecciones del centro, al mismo tiempo que instala la idea de que, de algún modo, la futura elección será ilegítima porque no hay oposición.

Esta situación da cuenta de que en muchos casos la "participación del alumno en el aula" (tal como fuera relevada en numerosos registros de clase) se restringe a responder las preguntas del docente, respuestas que no deben salirse del canon establecido, pues salirse del canon supone perturbar la voz del docente y la organización prevista para la clase, ocultándose la polémica subyacente en torno a que entiende cada uno por "participar", y la necesidad de acuerdos y disensos como parte constitutiva de la vida escolar.

Asimismo el lugar de lo grupal en el aula se centra en aspectos meramente técnicos, lejos de concebirse como una dimensión constitutiva de lo socialhistórico, y en tanto tal como "formaciones grupales" múltiples, singulares y cambiantes "como modo de pensar acerca de la complejidad de la realidad y como modos de acción en campos diversos de la actividad humana, nunca únicos ni estables, sino siempre estratégico, transformables, respondiendo a las demandas de la realidad y creando en su invención escenarios posibles para que los sujetos se formen como tales." (SOUTO, 1998, p. 34).

En otros registros de clase relevados el relato histórico se desarrolla como único y lineal, lejos de la posibilidad de pensar el pasado en término de encrucijadas a partir de las cuales eran posibles diversas opciones y recuperar así la compleja trama histórica en que se desarrollan las acciones de los sujetos, sus intenciones y sus consecuencias y de ese modo "darle sentido al pasado" a partir de la multiplicidad de interpretaciones que abren el juego para la confrontación, desestabilización y transformación de la propia identidad. 


\section{A modo de cierre}

La escuela como un espacio público de discusión democrática puede abrirse a múltiples preguntas y búsquedas, en el que se entrecrucen historias de vida, bisagras entre el pasado, el presente y el futuro, situadas en un contexto social e histórico sobre el cual es necesario reflexionar, pues el conocimiento histórico no se reduce a adquirir el conocimiento del pasado y las competencias acerca del tiempo histórico se adquieren pasando de formas simples de pensamiento a modos más complejos, que nos acercan a pensar el pasado y el presente en término de encrucijada y a generar espacios de aprendizaje ${ }^{8}$ que promuevan nuevas formas de interacción, producción y circulación de saberes y habiliten la organización de experiencias de participación compartidas entre los distintos actores que conforman la comunidad educativa, fundamento de una práctica crítica.

No es casual que en la sociedad argentina las alternativas colectivas se visualizaran como propias de un tiempo lejano. A través del disciplinamiento social la dictadura logró instalar una cultura del miedo y de la despolitización y "dejó fuertes improntas en el imaginario colectivo ulterior, en las prácticas políticas, sociales y culturales de la democracia que sucedió a la dictadura, y en las formas en que la sociedad argentina se piensa actualmente y aborda su pasado." (SIEDE, 2007) Despolitización que, como ya afirmamos, se vincula también con transformaciones producidas en los 90 en torno al rol del individuo y la política en la sociedad.

Sin embargo, en la actualidad consideramos que se han producido algunos cambios en relación a la cultura política argentina. En este sentido la política parece ser identificada por gran parte de la sociedad en general, y los jóvenes en particular, como herramienta de transformación de la realidad actual, alejándose de la valoración negativa expresada en el párrafo anterior. Tal vez el recuperar la política para comprender el pasado y actuar en el presente y de ese modo construir otros futuros, habitados por sujetos más libres y plenos, sea una tarea difícil pero necesaria de comenzar en la escuela.

Las "pistas" proporcionadas por la encuesta mencionada al principio de este trabajo y nuestra práctica cotidiana en la escuela son el entramado desde el cual profundizar el análisis crítico de las concepciones hegemónicas de la enseñanza de la historia y habilitar vínculos y prácticas participativas y democráticas que se constituyan en potente matriz de aprendizaje y punto de partida de nuevas alternativas tanto pedagógicas como políticas.

\footnotetext{
${ }^{8}$ Aprendizaje experiencial, sustento de la ciudadanía crítica.
} 


\section{Referencias}

ARGENTINA. Ley de Educación Nacional no 26.206. Promulgada el 27 de diciembre de 2006. Congreso de la Nación, Argentina, 2006.

AUYERO, J. Otra vez en la vía: notas e interrogantes sobre la juventud de sectores populares. Buenos Aires: Espacio Editorial, 1994.

BORBA, J. Cultura política, ideologia e comportamento eleitoral: alguns apontamentos teóricos sobre o caso brasileiro: Opinião Pública, Campinas, v. XI, n. 1, p. 147-168, mar. 2005.

BUENOS AIRES. Ley Provincial de Educación de la Provincia de Buenos Aires $\mathbf{n}^{\circ}$ 13.688. Promulgada 5 de julio de 2007. Senado y cámara de diputados de la provincia de Buenos Aires, Argentina, 2007.

CERRI, L. F; AMÉZOLA, G. de. Los jóvenes y la historia, una encuesta intercultural latinoamericana: algunos resultados. In: JORNADAS INTESESCUELAS DEPARTAMENTOS DE HISTORIA, 12. Actas..., Bariloche, 2009.

DIARIO LA NACIÓN. Hubo avances en la reunión de Bullrich con los alumnos y podrían levantarse las tomas. Buenos Aires,5 de octubre de 2012. Disponible en: <http:// www.lanacion.com.ar/1514634-bullrich-alumnos-y-gremialistas-ingresan-a-una-audienciade-conciliacion>. Acceso en: 11 oct. 2012.

DGCyE. Dirección General de Cultura y Educación de la Provincia de Buenos Aires. Resolución 4900/05, 15 de septiembre de 2005. La Plata, 2005.

DGCyE. Dirección General de Cultura y Educación de la Provincia de Buenos Aires. Diseño Curricular Construcción de la Ciudadanía. La Plata: Dirección General de Cultura yEducación de la Provincia de Buenos Aires, 2006.

DUSSEL, I. La escuela y la formación de la ciudadanía: reflexiones en tiempos de crisis. Buenos Aires: FLACSO, 1996. (Serie documentos e informes de investigación, n. 186).

ENTREVISTA a Martin Hopenhayn. Los jóvenes perciben que hay vacíos por llenar en la política. Diario Página 12, 2 de enero 2012. Disponible en: <http:/ /www.pagina12.com.ar/ diario/dialogos/21-184583-2012-01-02.html>. Acceso en: 11 oct. 2012.

FREIRE, P. Cartas a quien pretende enseñar. México: Siglo XXI, 1994.

HASSOUN, J. Los contrabandistas de la Memoria. Buenos Aires: Ediciones de La Flor, 2002.

IDAES, F. E. (Coordinación General); CHAVES, M. (Elaboración del informe). Proyecto Estudio Nacional sobre juventud en la Argentina. Informe. Investigaciones sobre juventudes en Argentina: estado del arte en ciencias sociales. La Plata - ciudad de Buenos Aires mayo de 2006.

NUÑEZ, P. Política y poder en la escuela media. La socialización política en el espacio escolar. Propuesta Educativa, n. 34, p. 130-132, nov. 2010.

NORA, V. Dicho por los protagonistas. Diario Página 12, 9 de septiembre de 2012. Disponible en: <http://www.pagina12.com.ar/diario/elpais/1-202991-2012-09-09.html>. Acceso en: 11 oct. 2012. 
ROMERO, L. A. (Coord.).La Argentina en la escuela: la idea de nación en los textos escolares. Buenos Aires: Eudeba, 2004.

RUIZ SILVA, A. Retos y posibilidades de la formación ciudadana. Revista Novedades Educativas, n. 220, p. 61-69, 2009.

RÜSEN, J. El desarrollo de la competencia narrativa en el aprendizaje histórico: una hipótesis ontogenética relativa a la conciencia moral. Propuesta Educativa, Buenos Aires, n. 7, p. 27-36, 1992.

RÜSEN, J. El libro de texto ideal: reflexiones entorno a los medios para guiar las clases de Historia. Revista Nuevas fronteras de la historia, Barcelona, v. 4, n. 12, abr. 1997.

SIEDE, I. La educación política: ensayos sobre ética y ciudadanía en la escuela. Buenos Aires: Paidós, 2007.

SOUTO, M. Las formaciones grupales en la escuela. Buenos Aires: Paidós, 1998.

Recebido em 26/12/2012

Versão final recebida em 26/05/2013

Aceito em 05/06/2013 